\title{
The enigma of non-gonococcal urethritis: role for Bacteroides ureolyticus
}

\author{
D A HAWKINS, ${ }^{*} \dagger$ E A R FONTAINE, ${ }^{*}$ B J THOMAS, ${ }^{*} \dagger$ Y L BOUSTOULLER, ${ }^{*}$ \\ D TAYLOR-ROBINSON*†
}

From the *Division of Sexually Transmitted Diseases, Clinical Research Centre, Harrow, Middlesex, and the $\dagger$ Jefferiss Research Wing of the Praed Street Clinic, St Mary's Hospital, Paddington, London

SUMMARY Although up to about half the cases of acute non-gonococcal urethritis (NGU) are caused by Chlamydia trachomatis organisms (chlamydiae) and a smaller, ill-defined, proportion probably by Ureaplasma urealyticum organisms (ureaplasmas), the aetiology of all cases is not understood. Clarification of the role of the anaerobe, Bacteroides ureolyticus, was sought in the current study. Seventy five chlamydia negative patients with NGU were treated on a double blind placebo controlled basis with metronidazole. After seven days more of the 35 patients given this drug tended to improve clinically than the $\mathbf{4 0}$ given the placebo, but the difference was not significant. Of 23 chlamydia negative but anaerobe positive men, however, $78 \%(7 / 9)$ receiving metronidazole responded clinically, but only 7\% (1/14) receiving placebo responded $(\mathrm{p}<0.001)$. Furthermore, whereas $78 \%$ of the anaerobe positive men given metronidazole recovered, only $23 \%(6 / 26)$ of the anaerobe negative men did so $(p<0.02)$. No further evidence for the role of ureaplasmas in the aetiology of NGU was obtained, but the data suggest that $B$ ureolyticus organisms, and perhaps other anaerobes, have an important role in a small proportion of cases and that the beneficial effects of metronidazole given on an empirical basis will be confined to anaerobe positive urethritis.

Evidence that Chlamydia trachomatis organisms (chlamydiae) are a cause of non-gonococcal urethritis (NGU) is overwhelming.' Chlamydial infection, however, is probably responsible for no more than about half the cases. Ureaplasma urealyticum organisms (ureaplasmas) are a likely cause of a further small, but ill-defined, proportion. ${ }^{23}$ Trichomonas vaginalis and herpes simplex virus account for no more than $5 \%$ of cases. ${ }^{3}$ There is no compelling evidence to implicate Mycoplasma hominis in NGU,$^{23}$ and the importance, if any, of $M$ genitalium still needs to be assessed. ${ }^{23}$ Clearly, therefore, not all NGU can be attributed to a known micro-organism and other infectious agents may have a role. ${ }^{34}$

In a study of the anaerobic microbial flora of the urethra, we found a Gram negative anaerobic bacillus appreciably more often in patients with NGU than in those without, and termed it a "NGU-associated anaerobe".s Subsequent work showed that this

Address for reprints: Dr D Taylor-Robinson, Division of Sexually Transmitted Diseases, Clinical Research Centre, Watford Road, Harrow, Middlesex HA1 3UJ

Accepted for publication 10 May 1987 anaerobe is a member of the species Bacteroides ureolyticus $^{6}$ and that, like all anaerobes, it is sensitive to metronidazole. ${ }^{7}$ This has provided us with the opportunity of using metronidazole, on a double blind placebo controlled basis, to treat chlamydia negative patients with NGU while undertaking clinical and comprehensive microbiological assessments. In this way we hoped to throw light not only on the value of metronidazole treatment from a clinical point of view, but at the same time provide further information on the importance of $B$ ureolyticus in NGU.

\section{Patients and methods}

The study group consisted of 146 unselected men who presented with uncomplicated NGU at the Praed Street Clinic in May 1984 to February 1986. Those treated with antibiotics in the previous three months were excluded, as were those who were allergic to metronidazole or unable to attend weekly on at least two occasions. All patients gave informed consent to participating in the study, which had been approved by the hospital ethics committee.

A urethral smear was Gram stained, and a diagnosis of NGU was made if there were five or more polymor- 
phonuclear leucocytes/high power microscope field $(x 800)$ in the absence of intracellular Gram negative diplococci. A specimen was taken also to culture Neisseria gonorrhoeae. Then an endourethral swab (MWE 142, Medical Wire and Equipment) was inserted two to four centimetres into the urethra to obtain a sample for the detection of chlamydiae, ureaplasmas, and $M$ hominis. A second endourethral swab was taken to search for $B$ ureolyticus, $T$ vaginalis, and Gardnerella vaginalis.

The test for chlamydiae, described below, was undertaken immediately and a result obtained within 30 minutes while the patient waited. If the result was positive the patient was treated with Deteclo (Lederle), which was routine clinic treatment, and withdrawn from the study. Chlamydia negative patients were given either metronidazole $\mathbf{4 0 0} \mathrm{mg}$ or a placebo twice daily for seven days on a random double blind basis. Patients were asked to avoid drinking alcohol and refrain from sexual intercourse. A full clinical and microbiological assessment was repeated seven and 14 days later. If urethritis persisted at day 7 the patient was treated with Deteclo. Treatment after 14 days was empirical, and long term follow up was undertaken rarely.

\section{MICROBIOLOGICAL PROCEDURES}

The first endourethral swab was rolled on a MicroTrak slide (Syva) and $C$ trachomatis elementary bodies sought by using a fluorescein conjugated chlamydial monoclonal antibody (Syva). ${ }^{8}$ The same swab was agitated in sucrose phosphate (2SP) medium without antibiotics, and this specimen was stored in liquid nitrogen and used later for attempted isolation of ureaplasmas and $M$ hominis by procedures described before.9 The second endourethral swab was expressed in anaerobic liquid medium, ${ }^{10}$ which was transported to the laboratory within four hours. Aliquots of $0.1 \mathrm{ml}$ were plated on a selective medium for B.ureolyticus," and the plates were incubated at $37^{\circ} \mathrm{C}$ for four to five days in an anaerobic chamber. Colonies were counted and identification confirmed by using tests for oxidase, urease production, and formate-fumarate growth requirement. ${ }^{67} T$ vaginalis was sought by introducing $0.25 \mathrm{ml}$ of the anaerobic

Table 1 Clinical response of 75 men with chlamydia negative non-gonococcal urethritis to treatment with either metronidazole or placebo for seven days

\begin{tabular}{llll}
\hline Treatment & $\begin{array}{l}\text { No free of } \\
\text { urethritis }\end{array}$ & $\begin{array}{l}\text { No with } \\
\text { persistent urethritis }\end{array}$ & $\begin{array}{l}\text { Total no of } \\
\text { men treated }\end{array}$ \\
\hline Metronidazole & 13 & 22 & 35 \\
Placebo & 8 & 32 & 40 \\
Total & 21 & 54 & 75
\end{tabular}

$\chi^{2}$ with Yates's correction, $1 \cdot 937 ; 0 \cdot 10<p<0 \cdot 2$. liquid transport medium into $4 \mathrm{ml}$ Trichomonas medium No 2 (Oxoid), which was incubated at $36^{\circ} \mathrm{C}$ for five days and examined microscopically every 24 hours. $G$ vaginalis was isolated by inoculating $0.1 \mathrm{ml}$ of the same transport medium on Columbia blood agar and selective human blood agar ${ }^{12}$ and incubating in $5 \%$ carbon dioxide in air at $37^{\circ} \mathrm{C}$ for 48 hours. Strains were identified as described elsewhere. ${ }^{13}$

\section{Results}

ISOLATION OF CHLAMYDIAE AND ENTRY TO THE TRIAL

Chlamydial elementary bodies were identified in specimens from $65(45 \%)$ of 146 men with NGU. Thus 81 men were chlamydia negative and were entered in the placebo controlled trial. Six of these men defaulted, leaving 75 for subsequent analysis, 35 of whom received metronidazole and 40 of whom received the placebo.

\section{OVERALL CLINICAL RESPONSE}

Table 1 shows the outcome after seven days for patients given either metronidazole or placebo. Of the 35 men given metronidazole, $13(37 \%)$ were free of urethritis, whereas eight $(20 \%)$ of the 40 given placebo were cured. The $95 \%$ confidence interval for the difference between these percentages is from $-6 \%$ to $35 \%$. Though the difference was not significant, there was clearly a trend towards improvement more often after treatment.

\section{CLINICAL RESPONSE IN RELATION TO $B$}

UREOLYTICUS

$B$ ureolyticus was identified initially in $21(32 \%)$ of the 65 chlamydia positive patients and in $23(31 \%)$ of the 75 chlamydia negative patients. Table 2 shows the results of subjecting the 23 chlamydia negative, anaerobe positive patients to either of the two treatment schedules. Patients given metronidazole had usually responded clinically after one week, whereas those given the placebo had usually not $(p=\langle 0 \cdot 01)$. Furthermore, treating the chlamydia negative patients with metronidazole was much more successful in those

Table 2 Clinical response of 23 chlamydia negative but Bacteroides ureolyticus positive men with non-gonococcal urethritis to treatment with either metronidazole or placebo for seven days

\begin{tabular}{llll}
\hline Treatment & $\begin{array}{l}\text { No free of } \\
\text { urethritis }\end{array}$ & $\begin{array}{l}\text { No with } \\
\text { persistent urethritis }\end{array}$ & $\begin{array}{l}\text { Total no of } \\
\text { men treated }\end{array}$ \\
\hline Metronidazole & 7 & 2 & 9 \\
Placebo & 1 & 13 & 14 \\
Total & 8 & 15 & 23 \\
\hline
\end{tabular}

$\chi^{2}$ with Yates's correction, $9 \cdot 136 ; 0 \cdot 001<p<0 \cdot 01$. 
who were anaerobe positive than in those who were anaerobe negative. Thus, seven $(78 \%)$ out of nine responded in the anaerobe positive group compared with only six $(23 \%)$ out of 26 in the anaerobe negative group $\left(\chi^{2}=6.39 ; \mathrm{p}<0.02\right)$.

\section{EFFECT OF TREATMENT ON B UREOLYTICUS}

Of the 23 men who initially yielded $B$ ureolyticus, nine received metronidazole and did not yield this anaerobe after one week. Specimens were not available for testing from four of the $\mathbf{1 4}$ men who received the placebo, but $B$ ureolyticus was isolated again from six of the remaining 10 .

\section{ROLE OF OTHER MICRO-ORGANISMS}

$T$ vaginalis was not detected in samples from any of the patients. $G$ vaginalis was found in two $(3 \%)$ of the 65 chlamydia positive patients and in six $(8 \%)$ of the 75 chlamydia negative patients, but there was no particular association with the anaerobe positive patients.

Ureaplasmas were isolated initially from $26(47 \%)$ and $M$ hominis from $10(18 \%)$ of the 55 chlamydia positive patients tested, and ureaplasmas from 39 (48\%) and $M$ hominis from $14(17 \%)$ of 81 chlamydia negative patients seen originally. Recovery from urethritis in the group of men given metronidazole occurred irrespective of the presence of ureaplasmas, and two men in this group who had persistent urethritis did not have ureaplasmas. Furthermore, the failure of men to recover when given the placebo could not be attributed to ureaplasmas as half of them did not harbour these organisms.

\section{Discussion .}

This study was made feasible by the rapid diagnosis of chlamydial infection and, therefore, the ability to recognise patients with chlamydia negative NGU and enter them into the trial on their first visit to the clinic. Of course, other microbiological investigations had to be made thereafter and their importance judged retrospectively. In a previous therapeutic study of chlamydia negative NGU we noted a strong placebo effect, ${ }^{14}$ and in the current study $20 \%$ of chlamydia negative patients with NGU responded clinically to the placebo. The proportion of chlamydia negative patients that responded to metronidazole was greater $(37 \%)$, although not significantly different. Even if the strong trend in favour of metronidazole continued, however, we estimate that we would have needed to double the size of the study to show with $90 \%$ probability $(p<0.05)$ that metronidazole was more effective clinically than the placebo. Chlamydia negative patients yielding $B$ ureolyticus from the urethra clearly responded to metronidazole much more often than to the placebo. This, together with our previous observation that this anaerobe occurred significantly more often in patients with NGU than in those without, ${ }^{5}$ suggests that $B$ ureolyticus has an important role in causing the disease. We do not believe that the occurrence of $B$ ureolyticus as often in patients with chlamydiae as in those without necessarily weakens the argument. The finding of chlamydiae in the urethras of patients with gonorrhoea does not militate against the pathogenicity of either chlamydiae or gonococci. We are aware, however, that because there are several putative pathogens, an antibiotic directed against one might affect others and so influence the interpretation of an antibiotic trial. In this regard, we cannot exclude the possibility that anaerobes other than $B$ ureolyticus, which are also sensitive to metronidazole, might be concerned and that $B$ ureolyticus is a marker for urethritis predominantly caused by anaerobes. $T$ vaginalis is also sensitive to metronidazole and must be considered in a study of this kind. Our failure to find it may reflect the fact that we did not culture subpreputial and prostatic fluid samples. It is unlikely to have made much difference to the interpretation of our observations, however, as the results of studies, at least those in the USA and Western Europe, indicate that $T$ vaginalis is responsible for less than $3 \%$ of all cases of NGU. ${ }^{3}$ Ureaplasmas and $M$ hominis are not sensitive to metronidazole and, although the study was not designed to look at the role of ureaplasmas in NGU, the results did not provide any further evidence that they were implicated. Indeed, their apparent lack of contribution to the production of anaerobe positive urethritis that is responsive to metronidazole strengthens the role of $B$ ureolyticus in this segment of disease.

At a practical level our findings should be considered with caution. Though they may give credence to the belief that metronidazole treatment has value for some patients with NGU, we submit that the beneficial effect will be confined only to those who are anaerobe positive. We do not know the extent to which $B$ ureolyticus might become resistant to tetracyclines, nor do we know how other anaerobes respond to tetracycline in comparison with metronidazole, so we cannot say categorically that it is not worthwhile to use metronidazole empirically after courses of tetracyclines have failed to cure NGU. As first line treatment, however, it has no place.

We thank Dr D Bedford (May and Baker Ltd) and the nursing staff of the Praed Street Clinic for their help in this study and Mr D Altman for his statistical advice.

\footnotetext{
References

1 Taylor-Robinson D, Thomas BJ. The role of Chlamydia trachomatis in genital-tract and associated diseases. J Clin Pathol 1980;33:205-33.

2 Taylor-Robinson D. Mycoplasma infections of the human
} 
urogenital tract with particular reference to non-gonococcal urethritis. Ann Microbiol (Paris) 1984;133A:129-34.

3 Hawkins DA, Taylor-Robinson D. Non-gonococcal urethritis in the male. In: Asscher AW, Brumfitt W, eds. Microbial diseases in nephrology. Chichester: John Wiley, 1986:47-67.

4 Hawkins DA, Taylor-Robinson D, Evans RT, Furr PM, Harris JRW. Unsuccessful treatment of non-gonococcal urethritis with rosoxacin provides information on the aetiology of the disease. Genitourin Med 1985;61:51-5.

5 Fontaine EA, Taylor-Robinson D, Hanna NF, Coufalik ED. Anaerobes in men with urethritis. British Journal of Venereal Diseases 1982;58:321-6.

6 Fontaine EAR, Bryant TN, Taylor-Robinson D, Borriello SP, Davies HA. A numerical taxonomic study of anaerobic Gramnegative bacilli classified as Bacteroides ureolyticus isolated from patients with non-gonococcal urethritis. J Gen Microbiol 1986;132:3137-46.

7 Fontaine EAR, Borriello SP, Taylor-Robinson D, Davies HA. Characteristics of a Gram-negative anaerobe isolated from men with non-gonococcal urethritis. J Med Microbiol 1984;17: $129-40$.

8 Thomas BJ, Evans RT, Hawkins DA, Taylor-Robinson D. Sensitivity of detecting Chlamydia trachomatis elementary bódies in smears by use of a fluorescein labelled monoclonal antibody: comparison with conventional chlamydial isolation. J Clin Pathol 1984;37:812-6.

9 Taylor-Robinson D, Furr PM. Recovery and identification of human genital tract mycoplasmas. Isr J Med Sci 1981;17: 648-53.

10 Fontaine EA, Taylor-Robinson D. Evaluation of liquid transport media for the isolation of anaerobic bacteria: relevance to genital tract specimens. $J$ Infect 1981;3:360-9.

11 Borriello SP, Fontaine EA, Hawkins D, Taylor-Robinson D. Development and evaluation of a selective medium for an anaerobe associated with non-gonococcal urethritis. In: Mårdh P-A, Taylor-Robinson D, eds. Bacterial vaginosis. Stockholm: Almqvist and Wiksell. 1984:167-71.

12 Totten PA, Amsel R, Hale J, Piot P, Holmes KK. Selective differential human blood bilayer media for the isolation of Gardnerella vaginalis. J Clin Microbiol 1982;15:141-7.

13 Taylor E, Phillips I. The identification of Gardnerella vaginalis. J Med Microbiol 1983;16:83-92.

14 Munday PE, Thomas BJ, Johnson AP, Altman DG, TaylorRobinson D. Clinical and microbiological study of non-gonococcal urethritis with particular reference to non-chlamydial disease. British Journal of Venereal Diseases 1981;57:327-33. 